\title{
Separation of copper flotation concentrates into density fractions by means of polytungstate aqueous solution
}

\author{
Andrzej Luszczkiewicz ${ }^{1, a}$, Piotr Karwowski ${ }^{1}$, Antoni Muszer ${ }^{2}$, and Jan Drzymala ${ }^{1}$ \\ ${ }^{1}$ Wroclaw University of Science and Technology, Faculty of Geoengineering, Mining and Geology, Wybrzeze \\ Wyspianskiego 27, 50-370 Wroclaw, Poland \\ ${ }^{2}$ Institute of Geological Sciences, University of Wroclaw, PI. Maksa Borna 9, 50-205 Wroclaw, Poland
}

\begin{abstract}
Industrial and laboratory flotation copper concentrates were subjected to separation into density fractions by means of heavy liquids in the form of sodium polytungstate aqueous solutions. For two samples, three densities factions were created, however in different density ranges. The density fractions were analyzed to establish the content of copper, lead, silver and organic carbon. The size of particles in both samples was similar $(90-95 \%-0.071 \mathrm{~mm})$. It was found that the lightest density fractions -2.45 and $-2.0 \mathrm{~g} / \mathrm{cm}^{3}$ still contained sulfide minerals scattered in the organic carbon bearing particles. Removal of the lightest density fraction $(-2.0$ $\mathrm{g} / \mathrm{cm}^{3}$ ) from the industrial concentrate samples led to considerable reduction of organic carbon ( $92 \%)$ and increasing its quality from 13 to $28 \% \mathrm{Cu}$. The mineralogical analysis of the heavy liquid separation products showed that most sulfide minerals were evenly dissemination in the heaviest density fractions with the recovery of $95-98 \%$. The lightest density fraction of -2.0 $\mathrm{g} / \mathrm{cm}^{3}$, being the richest in organic carbon, contained approximately $3 \%$ of unliberated sulfide minerals.
\end{abstract}

\section{Introduction}

One of laboratory separation methods used for mineralogical studies is gravity separation. This method provides density fractions of mineral matter with a high precision [1]. In mineralogical studies using gravity separation, heavy liquids are commonly applied to remove the heavy minerals fraction from the particulate matter as well as ground raw materials. In laboratory tests homogenous heavy liquids are applied. Gravity separation is also used on industrial scale using special suspensions called heavy media and the process is called heavy media separation.

Heavy media separation is especially useful for materials containing components of large differences in densities. The Kupferschiefer copper ore mined in Poland by KGHM Polska Miedz S.A. (shortly called KGHM) from the Lubin-Glogow Copper Basin (LGOM) belongs to this category because it contains both light carbonaceous shale and heavy sulfide minerals. The ore is of sedimentary-hydrothermal origin and contains three lithological fractions of different petrographic character, structure and mineralogical composition. These fractions are associated with three mineral

${ }^{a}$ Corresponding author: andrzej.luszczkiewicz@pwr.edu.pl 
layers called sandstone, carbonate and shale. The ore mined by KGHM is a mixture of the three lithological fractions and is processed in concentrating plants by flotation. The final flotation concentrates contain copper-bearing sulfides, gangue minerals (which decrease the quality of concentrates) and organic carbon which increased amount creates many technological problems in metallurgical processing at KGHM. The aim of the present study is to separate the organic carbon bearing particles by means of the gravity method using a heavy liquid to be able to obtain organic carbon concentrates which can be next characterize by chemical and mineralogical analyses. In the present research we wanted to answer the question, whether or not it is possible to remove liberated organic carbon bearing particles from flotation concentrates. It was assumed that the organic material, which is of natural origin and consists of different types of fossil substances, has density below 2.0 $\mathrm{g} / \mathrm{cm}^{3}$, that is much less than the common rock-forming minerals having density above $2.3-2.5 \mathrm{~g} / \mathrm{cm}^{3}$. The density of most metal-bearing minerals is above $3.0 \mathrm{~g} / \mathrm{cm}^{3}$. Such materials in mineralogy and petrography are referred to as heavy minerals. All of the sulfide minerals present in the investigated copper ore have densities above $4.0 \mathrm{~g} / \mathrm{cm}^{3}$ [2].

Recently, organic heavy liquids were commonly used for heavy media separation for research purpose. Presently, the organic heavy liquids are not applied in industry due to their high toxicity and carcinogenic properties. In addition to that, the organic liquids are not suitable for gravity separation of organic substances. Since 1980s the polytungstate salts aqueous solutions, which are non-toxic and non-reactive, have been used for separation, especially for different organic substances present in soils $[3,4]$. Also in sedimentology, the polytungstate salts solutions have been used as heavy media for separation of heavy minerals $[5,6]$.

To separate organic matter present in the copper ores of LGOM, which are mainly associated with black shale, similar methodology, as in the case of separation of organic matter from soil described by Morgun and Makarov [7], can be applied. In this work separation of organic ingredients from the soil required density of the heavy liquid $\geq 2.0 \mathrm{~g} / \mathrm{cm}^{3}$.

\section{Materials and methods}

Two samples of flotation copper concentrates were used in the investigations. Sample 1 was an industrial flotation concentrate from the Division of Concentrators in Lubin of KGHM and sample 2 which was a concentrate separated by laboratory flotation experiments using the copper ore processed at the Division of Concentrators in Lubin. Table 1 shows the particle size distribution of both samples, while the content of $\mathrm{Cu}, \mathrm{Ag}, \mathrm{Pb}$ and $\mathrm{C}_{\text {org }}$ in the investigated samples is given in Table 2 .

Aqueous solutions of sodium polytungstate $\left(3 \mathrm{Na}_{2} \mathrm{WO}_{4} \cdot 9 \mathrm{WO}_{3} \cdot \mathrm{H}_{2} \mathrm{O}\right.$, SPT) were used as a separation medium. This salt is able to provide density up to $3.1 \mathrm{~g} / \mathrm{cm}^{3}$. The solution densities were monitored by using a hydrometer.

The methodology of heavy liquid separation was based on the recommendations of Lewis and McConchie [8] discussed in details elsewhere [2]. Due to fine particle size of the samples and their slow natural sedimentation in a highly viscous polytungstate liquid, separations was supported by using a centrifuge which guarantees greater gravitational acceleration.

The samples were placed in centrifuge glass tubes and after thorough wetting by the heavy liquid, the suspension was centrifuged for 10 minutes at a speed of $3100 \mathrm{rpm}$. Then, the tubes were stored for 24 hours to achieve complete separation of the floating and sinking fractions. Each separated fraction was cleaned by using distilled water and then dried at $70^{\circ} \mathrm{C}$.

The separation operations started with the highest density liquid, and then the lighter separated fraction was subjected to subsequent separation in a less dense heavy liquid. Sample 1 was separated in two liquids having density of 3.00 and $2.45 \mathrm{~g} / \mathrm{cm}^{3}$, while sample 2 was separated in liquids with density of 2.30 and $2.00 \mathrm{~g} / \mathrm{cm}^{3}$. The obtained fractions were subjected to chemical analysis performed by CBJ sp. z o.o. to determine content of copper, silver, lead, and organic carbon. Additionally, sample 2 was subjected to the mineralogical analysis. The fractions separated in the heavy liquid were 
embedded in a resin and polished. The preparations were subjected to microscopic examination in the reflected light. The content of the sulfide minerals in the density fractions taking into account the size of the particles was determined.

Table 1. Particle size distribution of investigated samples.

\begin{tabular}{|r|r|r|}
\hline Size fraction, $\mathbf{~ m m}$ & Sample 1, \% & Sample 2, \% \\
\hline+0.071 & 11.18 & 6.76 \\
\hline $0.040-0.071$ & 25.06 & 27.30 \\
\hline$+0.020-0.040$ & 19.24 & 24.30 \\
\hline-0.020 & 44.53 & 41.64 \\
\hline Feed & 100.00 & 100.00 \\
\hline
\end{tabular}

Table 2. Content of $\mathrm{Cu}, \mathrm{Ag}, \mathrm{Pb}$ and Corg in investigated samples.

\begin{tabular}{|c|c|c|c|c|}
\hline & $\mathbf{C u}, \mathbf{\%}$ & $\mathbf{A g}, \mathbf{p p m}$ & $\mathbf{P b}, \mathbf{\%}$ & $\mathbf{C}_{\text {org }}, \mathbf{\%}$ \\
\hline Sample 1 & 12.87 & 455 & 5.42 & 9.44 \\
\hline sample 2 & 9.93 & 492 & 4.93 & 7.57 \\
\hline
\end{tabular}

\section{Results and discussion}

Table 3 summarizes the results of gravity separation of the industrial concentrate sample obtained from the Lubin Concentrator (sample 1), while Table 4 shows the results of separation using the concentrate produced by laboratory flotation of the copper ore provided by the Lubin Concentrator (sample 2). The results in Table 3 show that removal of organic carbon from the industrial concentrate by using gravity separation in heavy liquids would allow for a significant increase of its quality with relatively small losses in the yield. More than $88 \%$ (as recovery) of copper goes to the heaviest fraction $\left(>3.0 \mathrm{~g} / \mathrm{cm}^{3}\right)$ having the content of $\mathrm{Cu}$ equal to $28 \%$. This faction contains mostly ore minerals with a small amount $(1.5 \%)$ of organic carbon.

Removal of approximately $54 \%$ of organic carbon bearing particles (as recovery, fraction G1, Table 3) and mixing G3 and G2 fractions would improve the grade of concentrate from about 13 to over $17 \%$ of $\mathrm{Cu}$ with $4 \%$ of $\mathrm{Cu}$ losses. The fraction enriched in the organic carbon would contain over $18 \%$ of $\mathrm{C}_{\text {org }}$. The results indicated that for the industrial copper concentrates, despite fine sizes of particles (approximately $65 \%$ of the particles below $0.040 \mathrm{~mm}$, Table 1) there was a great number of organic carbon bearing particles containing probably a certain amount of very fine dispersed particles of copper sulfides. However, it can be concluded, the content of copper and organic carbon in the fraction G3 equal to $28 \%$ and $1.5 \%$, respectively, indicates the physical possibility of significant improvement of the Lubin flotation concentrates.

The aforementioned findings confirm the results of separation for the laboratory concentrate (sample 2, Table 4) performed in the heavy liquids at lower ranges of density. The main purpose of the experiments was separation of as light as possible fraction, in which one can expect the absence of heavy minerals, such as sulfides. As previously stated, the common rock-forming minerals have a density much larger than $3.0 \mathrm{~g} / \mathrm{cm}^{3}$.

The data on the density fraction $-2.0 \mathrm{~g} / \mathrm{cm}^{3}$ show, that despite a significant enrichment in the organic carbon (grade $23 \% \mathrm{C}_{\text {org }}$ ), it still contains about $1 \%$ of $\mathrm{Cu}, 150 \mathrm{ppm}$ silver and $1.5 \%$ lead. Although this sample particle size distribution was similar to the industrial concentrate (more than $65 \%$ of the particles below $0.040 \mathrm{~mm}$, Table 1), the laboratory concentrate contained less coarse 
particles $(+0.071 \mathrm{~mm})$. Therefore, it can be concluded that the degree of liberation of sulfide minerals in both samples was similar. The heaviest fraction in this series of tests with density of $>2.3 \mathrm{~g} / \mathrm{cm}^{3}$ contained $11.64 \% \mathrm{Cu}$ with recovery close to $98 \%$ and $4.65 \% \mathrm{C}_{\text {org }}$ with $65 \%$ recovery. It indicates that in the density fraction $>2.3 \mathrm{~g} / \mathrm{cm}^{3}$ there is a significant amount of unliberated organic carbon bearing particles intergrown with sulfide minerals.

Table 3. Results of gravity separation of industrial copper concentrate (sample 1), $\gamma$ - weight percent (yield), $\lambda$ component content, $\varepsilon$ - component recovery.

\begin{tabular}{|c|c|c|c|c|c|c|c|c|c|}
\hline \multirow{2}{*}{$\begin{array}{l}\text { Density fractions } \\
\mathrm{g} / \mathrm{cm}^{3}\end{array}$} & \multirow{2}{*}{$\begin{array}{c}\text { yield } \\
\gamma, \%\end{array}$} & \multicolumn{2}{|c|}{$\mathbf{C u}$} & \multicolumn{2}{|c|}{ Ag } & \multicolumn{2}{|c|}{$\mathbf{P b}$} & \multicolumn{2}{|c|}{$\mathbf{C}_{\text {org }}$} \\
\hline & & $\lambda, \%$ & $\varepsilon, \%$ & $\lambda, \mathrm{ppm}$ & $\varepsilon, \%$ & $\lambda, \%$ & $\varepsilon, \%$ & $\lambda, \%$ & $\varepsilon, \%$ \\
\hline $\mathrm{G} 3(>3.00)$ & 43.03 & 27.95 & 88.24 & 958 & 77.69 & 7.74 & 72.89 & 1.51 & 7.72 \\
\hline $\mathrm{G} 2(2.45-3.00)$ & 32.02 & 3.40 & 7.99 & 224 & 13.52 & 2.42 & 16.96 & 10.13 & 38.52 \\
\hline G1 $(<2.45)$ & 24.95 & 2.06 & 3.77 & 187 & 8.79 & 1.86 & 10.16 & 18.14 & 53.76 \\
\hline calculated feed & 100.00 & 13.63 & 100.00 & 531 & 100.00 & 4.57 & 100.00 & 8.42 & 100.00 \\
\hline assayed feed & & 12.87 & & 455 & & 5.42 & & 9.44 & \\
\hline
\end{tabular}

Table 5 summarizes the balance of ore minerals according to mineralogical analyses of the fractions separated by means of polytungstate heavy liquid from the laboratory concentrate (sample 2). Table 5 shows the balance, and independently, the sum of the identified ore minerals and separately major sulfide minerals present in the concentrate. As can be seen from Table 3, almost all copper sulfide mineral particles were transferred, with the recovery of $97-98 \%$, to the heaviest $>2.3$ $\mathrm{g} / \mathrm{cm}^{3}$ density fraction. A total of about $3 \%$ of the ore minerals (recovery) remained in the $2.00-2.30$ $\mathrm{g} / \mathrm{cm}^{3}$ density fraction and lightest density fraction $<2.00 \mathrm{~g} / \mathrm{cm}^{3}$. The content of the ore minerals in the lightest fractions was approximately 5\%. There is no doubt that this should be attributed to dispersion of the unliberated sulfides particles in the organic carbon bearing particles. In accordance with the previously cited literature, the highest content of organic carbon in the tested concentrates was in the density fractions below 2.00 and below $2.30 \mathrm{~g} / \mathrm{cm}^{3}$.

A small amount of the lightest fraction (Tables 4 and 5) having density of $<2.00 \mathrm{~g} / \mathrm{cm}^{3}$ indicates a lack in the tested flotation concentrates particles sulfide minerals liberated from organic carbon bearing particles. Taking into account relatively small particles of the raw investigated samples, separation by means of physical methods gives products which would be enriched in organic carbon and not containing dispersed sulfides seems to be impossible.

\section{Conclusions}

Gravity separation tests were performed using two samples of copper flotation concentrates with similar particle distributions. More than $65 \%$ of particles were $-0.040 \mathrm{~mm}$ in size. Both samples were subjected to separation into the density fraction by means of heavy liquids prepared as aqueous solutions of sodium polytungstate at different ranges of density. Sample 1 was separated in heavy liquids into heavier densities fractions and the goal was to extract minerals of the highest density. Based on the obtained results, it was concluded that the $\mathrm{Cu}$ content equal to $28 \%$ (fraction $\mathrm{G} 3$ in Table 3) was reached when the content of $\mathrm{C}_{\text {org }}$ was $1.5 \%$. This indicates on a possible significant improvement of the currently produced Lubin concentrates. 


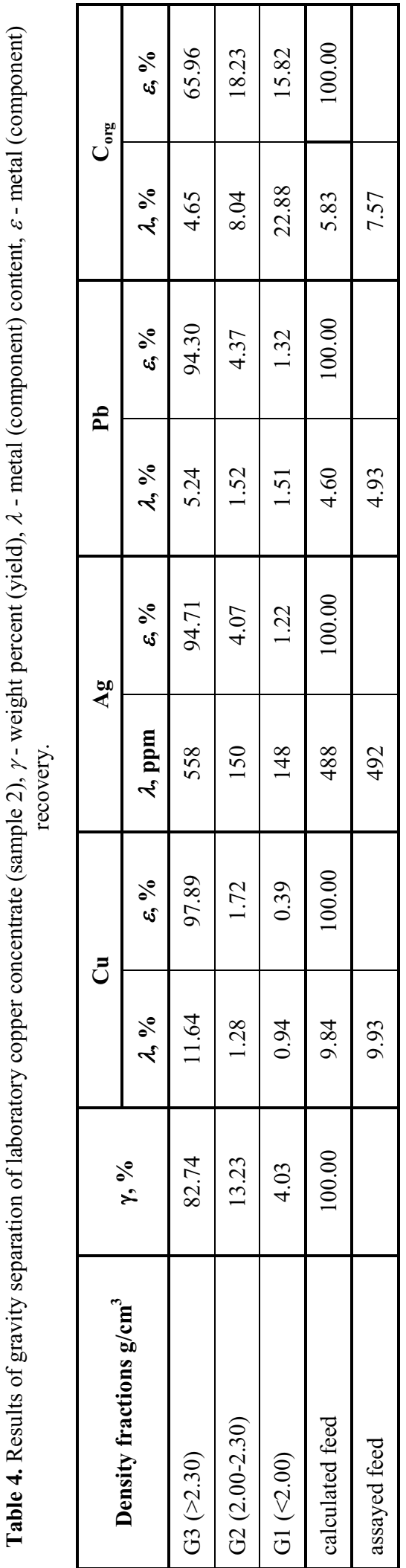

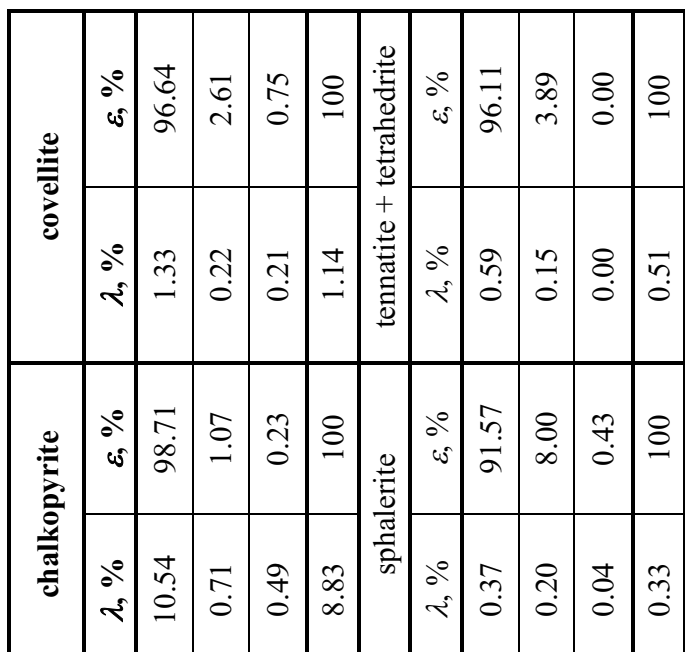

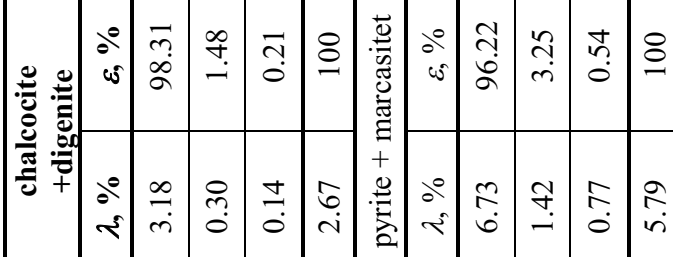

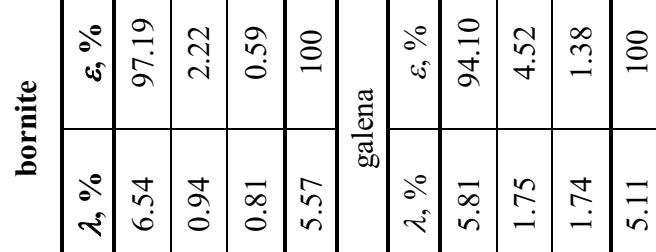

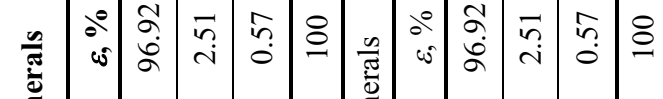

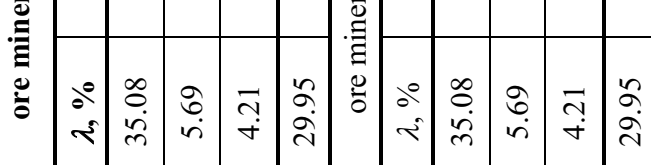

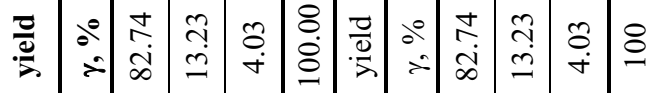

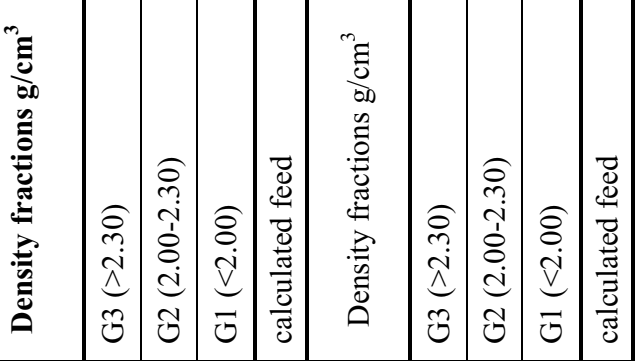


Sample 2 was separated in heavy liquids of lower density, to produce the density fraction $<2.0$ $\mathrm{g} / \mathrm{cm}^{3}$. This density was considered in the literature as the limit of determination of organic carbon bearing particles. The fraction of this density of the tested flotation concentrates contained mainly particles having a high organic carbon content which exceeded $20 \%$. These particles contained scattered unliberated fine particles of sulfide minerals in the amount of approximately $5 \%$. This fraction represented less than $20 \%$ of the total mass of the concentrate.

The gravity separation experiments using the flotation concentrates and heavy liquids indicate that for the used particle size distribution, it is not possible to remove the organic carbon bearing particles without very fine sulfide mineral particles.

\section{Acknowledgement}

The authors would like to thank Dr. Przemyslaw B. Kowalczuk for his valuable remarks. Financial support by the Wroclaw University of Technology Statutory Research Grant 0401/0186/15 is also greatly acknowledged.

\section{References}

1. G.S. Berger, I.A. Yefimov I.A., Metody vydelenya monomineralnykh fraktsii. Izd. 2, Gosgeoltekhizdat (Бергер Г.С., Ефимоф И.А., Методы выделения мономинералных фракции. Изд. 2, Госгеолтехиздат, Москва 1962)

2. A. Luszczkiewicz, Monograph No. 36 (Prace Naukowe Instytutu Gornictwa PWR, 2002)

3. N.M. Savage, J. Micropaleontol.,7(1), 39 (1988)

4. D. Munsterman; S. Kerstholt, Review of Palaeobotany and Palynology, 91(1-4), 417 (1996)

5. J.A. Callahan, J. Sedimentary Res., 57(4), 765 (1987).

6. J.A. Commeau, L.J. Poppe, R.F. Commeau, U.S. Geolog. Survey Circular, No. 1071, 1 (1992)

7. E.G. Morgun, M.I. Makarov, Eurasian Soil Sci., 44(4), 394 (20110

8. D.W Lewis, D. McConchie, Analytical Sedimentology (Chapman and Hall, London, 1994) 